\title{
Observed magnetic resonance imaging changes in pediatric patients treated with stereotactic radiosurgery for intracranial tumors
}

\author{
Sameer K. Nath • Ruben Carmona • Brent S. Rose • \\ Daniel R. Simpson • Michelle Russell • \\ Joshua D. Lawson • Arno J. Mundt • Kevin T. Murphy
}

Received: 10 July 2010 / Accepted: 30 July 2010 / Published online: 7 October 2010

(C) The Author(s) 2010. This article is published with open access at Springerlink.com

\begin{abstract}
Purpose This study seeks to characterize magnetic resonance imaging (MRI) changes following stereotactic radiosurgery (SRS) of pediatric brain malignancies.

Methods Serial MRI evaluations were performed on 21 lesions treated with SRS for either medulloblastoma $(n=12)$, juvenile pilocytic astrocytoma $(n=4)$, ependymoma $(n=2)$, atypical rhabdoid teratoid tumor $(n=2)$, or pineocytoma $(n=1)$. Prescription doses ranged from 14 to $30 \mathrm{~Gy}$ in one to five fractions. Tumor response was qualified as complete (CR), partial (PR), stable disease (SD), or progressive disease (PD) according to the RECIST v1.1. Median radiographic follow-up after SRS was 17 months. Results A total of 80 follow-up MRI scans were reviewed with a median of eight per patient. During serial MRI evaluation, eight lesions met criteria for PD at a median of 6 months. However, of these, three (37\%) represented transient tumor edema with two lesions later developing a
\end{abstract}

Meeting This research was submitted in part to the 52nd Annual Meeting of the American Society for Therapeutic Radiology and Oncology (ASTRO), San Diego, CA, 2010

S. K. Nath · R. Carmona • B. S. Rose • D. R. Simpson •

M. Russell $\cdot$ J. D. Lawson • A. J. Mundt $\cdot$ K. T. Murphy

Department of Radiation Oncology and Center for Advanced

Radiotherapy Technologies,

Rebecca and John Moores Cancer Comprehensive Cancer Center,

University of California San Diego,

La Jolla, CA, USA

S. K. Nath $(\bowtie)$

Department of Radiation Oncology,

UCSD Moores Cancer Center,

3855 Health Sciences Dr. \#0843,

La Jolla, CA 92093-0843, USA

e-mail: sameerknath@gmail.com
$\mathrm{CR}$ at a median of 15 months and one persisting as SD at 12 months. The remaining five lesions were true local failures. Of the 13 lesions that did not show evidence of $\mathrm{PD}$, a CR was obtained in 11 lesions at a median of 3 months (range, 2-6), and SD was seen in the remaining two tumors at last follow-up.

Conclusion Lesion enlargement following SRS for pediatric intracranial tumors is common, and a proportion of patients meeting requirements for $\mathrm{PD}$ at early radiographic follow-up may later develop complete resolution of their lesions. Physicians should be aware of these radiographic changes to avoid unwarranted medical and surgical interventions.

Keywords Stereotactic radiosurgery (SRS) - Brain tumor . Pediatric $\cdot$ Magnetic resonance imaging (MRI)

\section{Introduction}

Intracranial malignancies are the most common solid tumors of childhood and the second most common pediatric cancer after hematologic malignancies [13]. The standard of care for children greater than 3 years with central nervous system (CNS) tumors is a multidisciplinary approach combining surgery, radiotherapy, and chemotherapy [22]. Traditionally, conventional radiotherapy techniques have been associated with modest efficacy yet carry a significant risk for late treatment-related morbidity, including endocrinopathies, osteopenia/osteonecrosis, neurocognitive changes, growth alterations, and second malignancies [30]. The clinical implementation of stereotactic radiosurgery (SRS) for small volume lesions or as adjuvant therapy following sub-total resections has several potential advantages over traditional radiotherapy techniques, including the ability to deliver higher doses with 
steeper gradients, thereby allowing for increased tumor control and decreased treatment-related side effects. Reports on SRS for pediatric intracranial tumors are still immature but suggest better toxicity profiles over conventional or whole brain radiation therapy techniques $[2,7,9$, $11,12,16,17,19,21,27]$, likely secondary to lower volumes of normal brain tissue irradiation [20]. For these reasons, SRS will likely have a more integral role in the management of pediatric brain tumors in the near future.

One difficulty in treating patients with SRS is disease surveillance. Following stereotactic radiosurgery (SRS) of adult intracranial malignancies, it can be difficult to distinguish between radiation effect and tumor progression on magnetic resonance imaging (MRI) [6, 15, 24, 25]. Many physicians anticipate a near-complete response to occur within 20 weeks of therapy, much like that seen for metastases [24]. However, transient tumor edema or stable disease following SRS can occur for several months [1, 15, $24,25]$, leading to disagreements regarding the efficacy of SRS therapy. ${ }^{18} \mathrm{~F}$-flurodeoxyglucose positron emission tomography (FDG-PET) [3], ${ }^{11} \mathrm{C}-$-methionine PET [28, 29], single photon emission computed tomography (SPECT) [18, 26], T1/T2 matching [15], and biopsy [14] have all been studied to assess their clinical utility in discriminating between radiation effect and disease progression; however, there is no universally accepted standard regarding the use and interpretation of these tests. Many of these tests are also not routinely available in all clinical practices.

Since erroneous diagnosis of lesion progression can lead to unwarranted interventions with little potential for benefit, it is important to understand these imaging changes. In particular, since the application of SRS for pediatric intracranial tumors is a relatively new therapeutic approach, few guidelines are available regarding the MRI changes following therapy. As such, we have performed a review of MRI scans on a series of children treated with SRS at our institution in order to better clarify the natural course of post-SRS intracranial lesions followed by MRI.

\section{Methods}

Institutional review board approval was obtained prior to the initiation of this study. A retrospective review of patient records was performed to identify all patients treated with SRS for primary intracranial pediatric tumors. Twelve patients at the University of California San Diego were identified meeting this criteria. The clinical characteristics of these patients are summarized in Table 1. Median patient age was 12 (range 4-22). Largest tumor diameters ranged from less than 5 to $31 \mathrm{~mm}$.

The decision to treat with radiosurgery for primary, recurrent, or residual disease was made based on history of previous therapeutic interventions and/or consensus at tumor board. Prescription dose delivered to the planning target volume ranged from 14 to 30 Gy delivered in one to five fractions (Table 1). Our technique for pediatric SRS has been previously described [17]. All patients were treated between September 2006 and October 2009.

All available MRIs were reviewed for each patient, and lesions were grouped into the following categories based on the revised Response Evaluation Criteria In Solid Tumors version $1.1[8]$ :

Table 1 Clinical characteristics

\begin{tabular}{|c|c|c|c|c|c|c|c|}
\hline Patient & Age & Diagnosis & No. of lesions & Radiation & Chemotherapy $^{a}$ & Surgery ${ }^{\mathrm{b}}$ & Follow-up time (months) \\
\hline 1 & 12 & JPA recurrence & 1 & $16 \mathrm{~Gy} \times 1$ & No & Yes & 32 \\
\hline 2 & 4 & JPA recurrence & 1 & $6 \mathrm{~Gy} \times 5$ & No & Yes & 8 \\
\hline 3 & 14 & JPA residual & 1 & $20 \mathrm{~Gy} \times 1$ & No & Yes & 31 \\
\hline 4 & 12 & JPA residual & 1 & $20 \mathrm{~Gy} \times 1$ & No & Yes & 12 \\
\hline 5 & 18 & MB recurrence & 3 & $20 \mathrm{~Gy} \times 1$ & Yes & Yes & 3 \\
\hline 6 & 13 & MB recurrence & 4 & $10 \mathrm{~Gy} \times 2$ & Yes & Yes & 4 \\
\hline 7 & 12 & MB metastasis & 1 & $14 \mathrm{~Gy} \times 1$ & Yes & Yes & 17 \\
\hline 8 & 4 & MB metastasis & 4 & $6 \mathrm{~Gy} \times 5$ & Yes & Yes & 2 \\
\hline 9 & 22 & EM recurrence & 1 & $6 \mathrm{~Gy} \times 5$ & No & Yes & 16 \\
\hline 10 & 8 & EM recurrence & 1 & $20 \mathrm{~Gy} \times 1$ & Yes & Yes & 25 \\
\hline 11 & 3 & ATRT recurrence & 2 & $20 \mathrm{~Gy} \times 1$ & Yes & Yes & 21 \\
\hline 12 & 19 & Pineocytoma & 1 & $5 \mathrm{~Gy} \times 1$ & No & Yes & 39 \\
\hline
\end{tabular}

Gy gray, $M B$ medulloblastoma, JPA juvenile pilocytic astrocytoma, EM ependymoma, ATRT atypical rhabdoid teratoid tumor

${ }^{\text {a }}$ Prior to or concurrent with SRS

${ }^{\mathrm{b}}$ Prior to SRS 

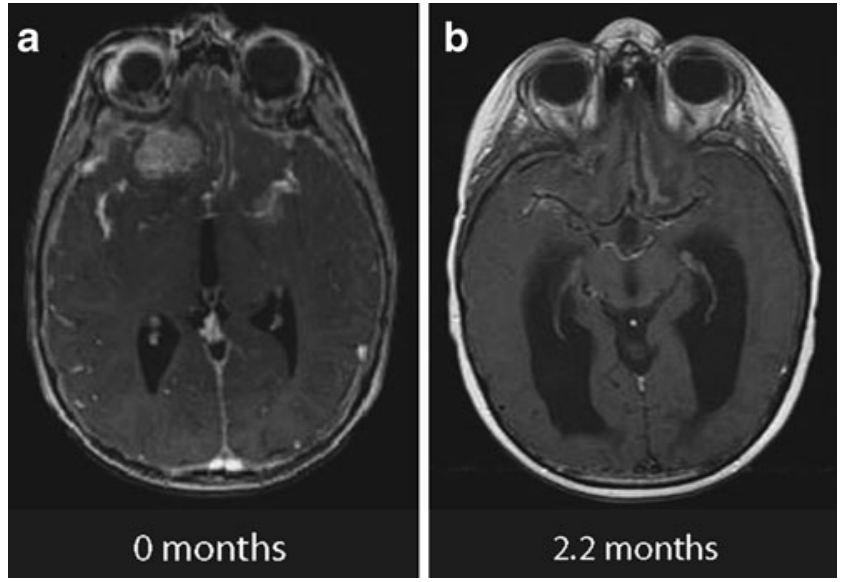

Fig. 1 Example of a complete response seen by MRI 2 months following treatment with SRS for a medulloblastoma metastasis of the right frontal lobe (patient 8). a Diagnostic MRI. b Follow-up MRI scan at 2.2 months

1. Complete response (CR): near-complete disappearance of target lesion

2. Partial response (PR): at least $30 \%$ decrease in sum of target lesion diameters

3. Progressive disease (PD): at least $20 \%$ increase in sum of target lesion diameters

4. Stable disease (SD): Insufficient change to qualify as $\mathrm{CR}, \mathrm{PR}$, or PD

The determination of actual disease progression (local failure) was based on clinical and imaging characteristics at follow-up and discussion at tumor boards attended by radiation, medical, and neurosurgical oncologists, as well as pathologists and neuroradiologists. Where relevant, FDGPET, SPECT, and/or biopsy was performed to assist in the discrimination between radiation effect and true disease progression.

To compare lesion size on follow-up MRI scans to the original planning isodose curves, follow-up MRI scans and the planning CT were fused using a rigid auto-registration tool (Varian Eclipse ${ }^{\mathrm{TM}}$ ) and subsequently manually verified.

\section{Results}

Median radiographic follow-up after SRS was 17 months (range, 2-39). A total of 80 follow-up MRI scans were reviewed with a median of eight per patient (range, 1-13). During serial MRI evaluation, 11 lesions (52\%) developed a CR (without prior lesion growth large enough to qualify as PD) at median time of 3 months (range, 2-6) following SRS (Fig. 1; Table 2). Persistent SD without prior lesion enlargement was seen in two lesions $(10 \%)$ at the time of analysis. The remaining eight lesions (38\%) met criteria for PD at a median of 6 months (range, 3-20). However, of these, three (37\%) represented transient tumor edema with two (histology: juvenile pilocytic astrocytoma, atypical rhabdoid teratoid tumor (ATRT)) later developing a CR at a median of 15 months (Figs. 2 and 3 ) and one persisting as SD at 12 months. Both patients who developed CR after
Table 2 Radiographic response of each lesion following SRS
$S D$ stable disease, $P D$ progressive disease, $C R$ complete response, $P R$ partial response, $M B$ medulloblastoma, $J P A$ juvenile pilocytic astrocytoma, $E M$ ependymoma, $A T R T$ atypical rhabdoid teratoid tumor, $f / u$ follow-up

\begin{tabular}{|c|c|c|c|}
\hline Patient & Diagnosis & Imaging progression (months, following SRS) & Outcome \\
\hline 1 & \multirow[t]{2}{*}{ JPA recurrence } & $\mathrm{PD} \rightarrow \mathrm{PR}$ (at 17 ) $\rightarrow \mathrm{CR}$ (at 20 ) & $\mathrm{CR}$ as of last $\mathrm{f} / \mathrm{u}$ \\
\hline 2 & & $\mathrm{SD} \rightarrow \mathrm{PD}($ at 4$) \rightarrow$ Failed & Local failure \\
\hline 3 & \multirow[t]{2}{*}{ JPA residual } & $\mathrm{SD} \rightarrow \mathrm{PD}($ at 15$) \rightarrow$ Failed & Local failure \\
\hline 4 & & $\mathrm{SD} \rightarrow \mathrm{PD}($ at 7$) \rightarrow \mathrm{SD}$ (at 11$)$ & SD as of last $\mathrm{f} / \mathrm{u}$ \\
\hline $\begin{array}{l}5 \\
5\end{array}$ & \multirow[t]{6}{*}{ MB recurrence } & \multirow[t]{2}{*}{$\mathrm{CR}($ at 2$)$} & \multirow[t]{6}{*}{$\mathrm{CR}$ as of last $\mathrm{f} / \mathrm{u}$} \\
\hline 5 & & & \\
\hline 6 & & \multirow[t]{4}{*}{$\mathrm{PR} \rightarrow \mathrm{CR}$ (at 4) } & \\
\hline 6 & & & \\
\hline 6 & & & \\
\hline 6 & & & \\
\hline 7 & \multirow[t]{5}{*}{ MB metastasis } & $\mathrm{SD} \rightarrow \mathrm{CR}$ (at 6) & \multirow[t]{3}{*}{$\mathrm{CR}$ as of last $\mathrm{f} / \mathrm{u}$} \\
\hline 8 & & \multirow[t]{2}{*}{$\mathrm{CR}($ at 2$)$} & \\
\hline 8 & & & \\
\hline 8 & & \multirow[t]{2}{*}{$\mathrm{SD}$ (at 2) } & \multirow[t]{2}{*}{$\mathrm{SD}$ as of last $\mathrm{f} / \mathrm{u}$} \\
\hline 8 & & & \\
\hline 9 & \multirow[t]{2}{*}{ EM recurrence } & $\mathrm{SD} \rightarrow \mathrm{PD}($ at 8$) \rightarrow$ Failed & \multirow[t]{2}{*}{ Local failure } \\
\hline 10 & & PD (at 3) $\rightarrow$ Failed & \\
\hline 11 & \multirow[t]{2}{*}{ ATRT recurrence } & $\mathrm{SD} \rightarrow \mathrm{PD}($ at 4$) \rightarrow \mathrm{CR}$ (at 10 ) & $\mathrm{CR}$ as of last $\mathrm{f} / \mathrm{u}$ \\
\hline 11 & & $\mathrm{SD} \rightarrow \mathrm{PD}($ at 20$) \rightarrow$ Failed & Local Failure \\
\hline 12 & Pineocytoma & CR (at 3) & $\mathrm{CR}$ as of last $\mathrm{f} / \mathrm{u}$ \\
\hline
\end{tabular}


Fig. 2 Example of transient tumor edema and sustained contrast enhancement at several time points following treatment with SRS of a recurrent juvenile pilocytic astrocytoma (patient 1). a Diagnostic MRI. b-i Follow-up MRI scans at different time points
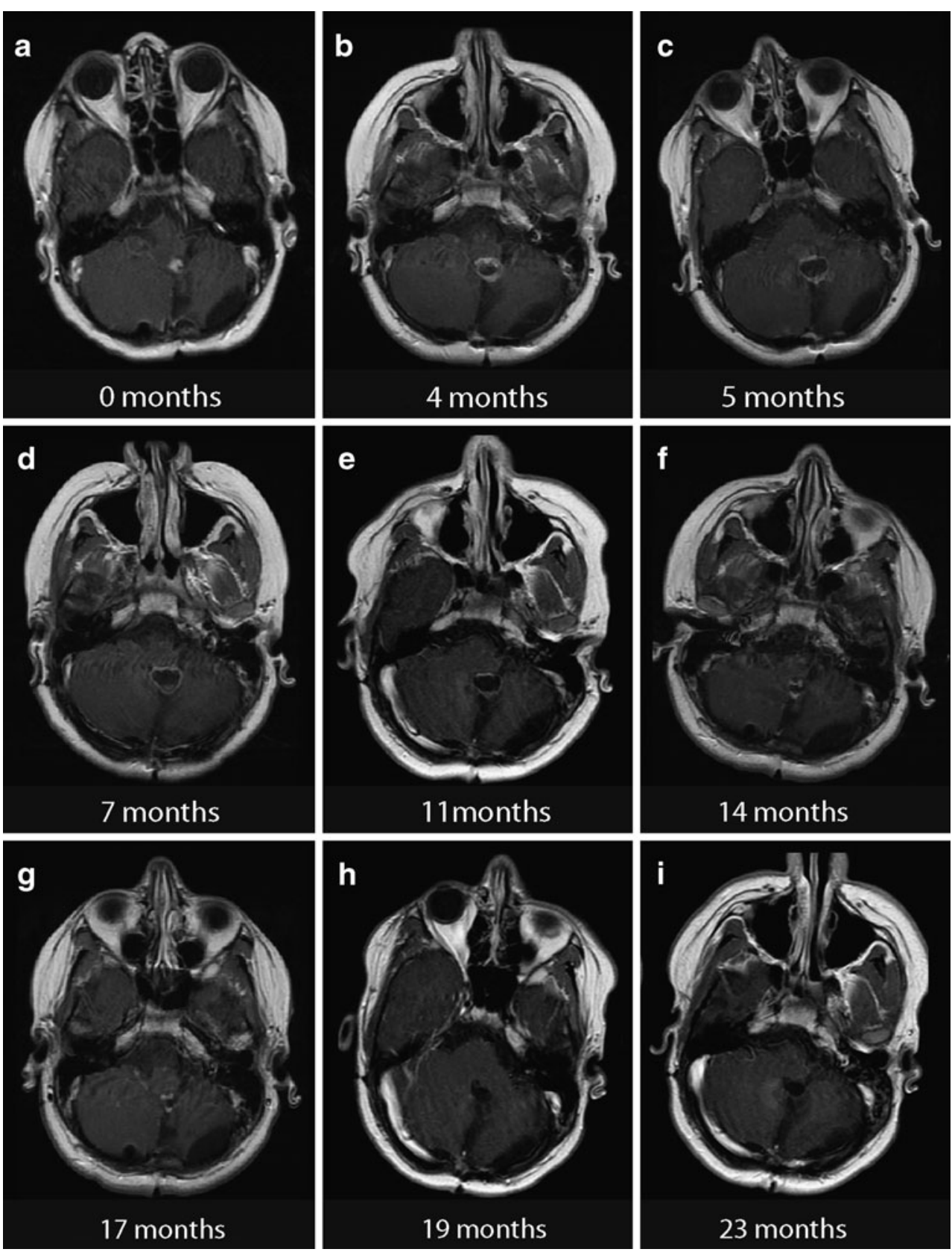

initial PD were asymptomatic during the period of active surveillance and have shown no evidence of local progression now at 22 and 32 months post-SRS. The remaining five lesions were true local failures. The extent of transient lesion enlargement in patient 11 (Tables 1 and 2) was found to correspond with the $16 \mathrm{~Gy}$ isodose line $(80 \%$ of prescription dose) from the planning CT (Fig. 4).

\section{Discussion}

Approximately $66 \%$ of all children with intracranial tumors will achieve long-term survival (greater than 5 years) [5].
Survivors of childhood brain malignancies are however more likely to be functionally impaired and develop serious long-term health problems, including endocrine deficiencies, physical disabilities, chronic fatigue, and learning problems, than survivors of non-CNS malignancies [4, 10, 23]. This is in part related to the high morbidity associated with medical, surgical, and radiotherapeutic interventions, which have greater impact on the more vulnerable developing CNS of children [30]. For this reason, minimizing unwarranted therapeutics is essential for ensuring high quality of life following tumor therapy. In this study, we have attempted to characterize the observed MRI changes following pediatric intracranial SRS in an effort 
Fig. 3 Example of transient tumor enlargement with heterogeneous contrast enhancement at several time points following treatment with SRS for an ATRT (patient 11). a Diagnostic MRI. b-f Follow-up MRI scans at different time points
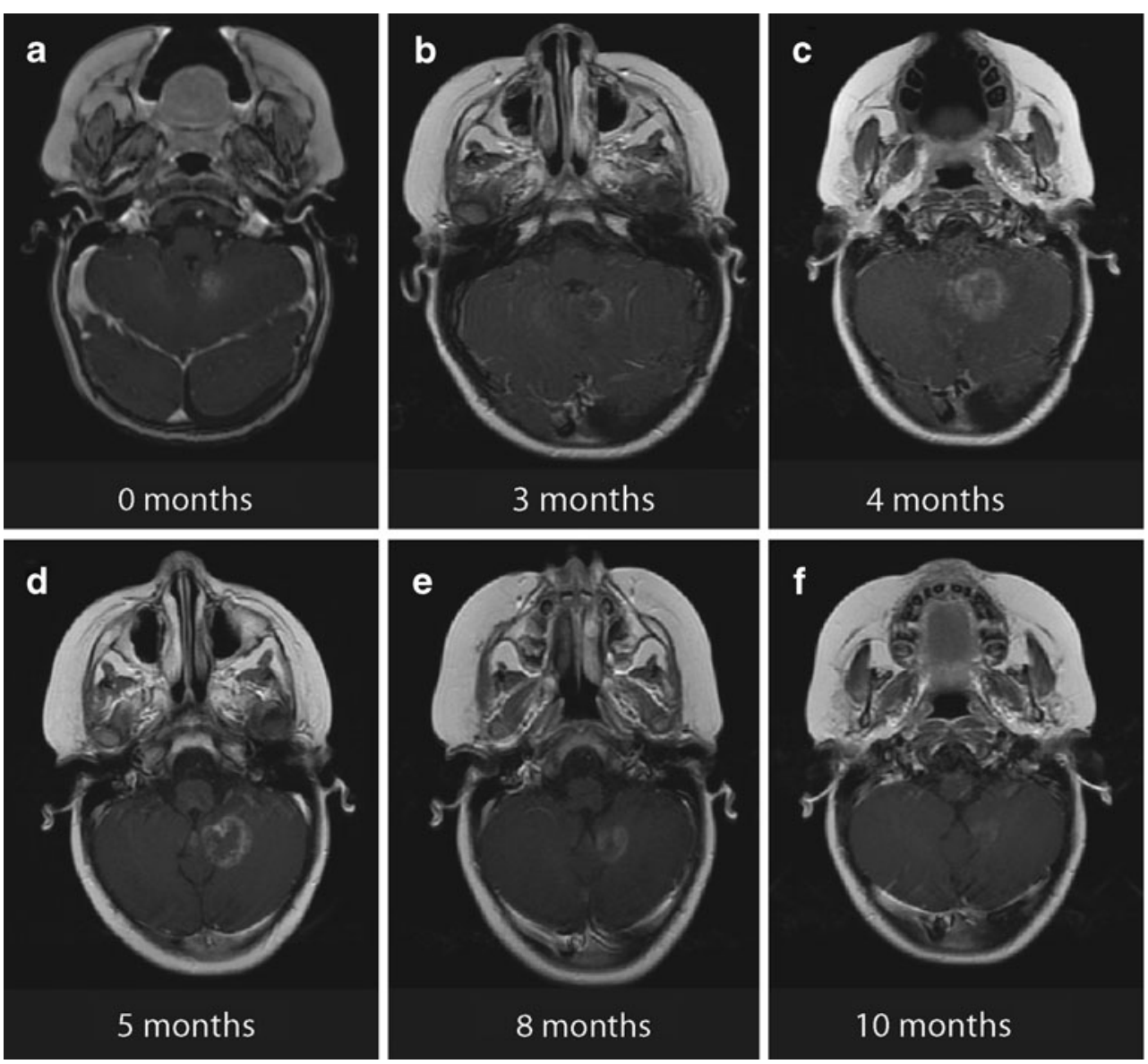

to elucidate the imaging characteristics of SRS-treated lesions in order to better guide disease surveillance in these patients. Overall, we have found that the response to SRS is variable with a significant portion of lesions that initially enlarge not representing true local failures. Improved awareness of this phenomenon may reduce the number of unnecessary interventions and improve long-term outcomes of adult survivors of these childhood malignancies.

Complete resolution of lesions by MRI was common following pediatric SRS. In Fig. 1, a CR within 3 months of SRS is shown for a 4-year-old patient who received 30 Gy in five fractions for a medulloblastoma metastasis. This rapid and complete disappearance of the lesion occurred frequently in our patient cohort, as over half of all treated lesions developed a CR within 6 months of therapy. Previous research on adult intracranial metastases has found that a CR develops in 56\% of lesions treated within 5 months of Gamma Knife radiosurgery [24], supporting the findings in this study. As such, physicians should recognize this as the predominant response pattern following SRS.

Despite the favorable overall response to SRS, transient lesion enlargement was found in roughly one third of patients of who met requirements for $\mathrm{PD}$ at any time following SRS. This problem is further exacerbated by the timing of the CR after transient edema, which occurred at a median of 15 months following therapy, long after the 6-month window where most $\mathrm{CR}$ are seen. In the example shown in Fig. 2, the patient developed persistent homogenous ring enhancement for at least 17 months following SRS. This patient was asymptomatic clinically and had cystic changes indicative of radiation effect. As such, active surveillance with serial MRI evaluations was deemed appropriate.

Similarly, in Fig. 3, an example of transient lesion enlargement is shown for a 4 year-old with two ATRT tumors treated with single-fraction SRS to 20 Gy. The patient developed transient swelling of one lesion with heterogeneous contrast enhancement resembling recurrent disease. As the patient was asymptomatic clinically and further diagnostic studies (including FDG-PET and SPECT) were equivocal, the patient was actively followed by serial MRI scans. At 10 months post-SRS, she developed a CR on MRI and remained asymptomatic. Figure 3 demonstrates that at the time of maximal lesion size during MRI surveillance, the 16 Gy line well-approximated the area of enlargement, suggesting that the observed inflammatory response could be explained by the treatment volume. Although the complete extent of the edema is not contained within the 16 Gy line in the axial view, some error is to be 
Fig. 4 Extent of tumor enlargement corresponding to isodose curves on planning CT. a Planning target volume on the original planning CT for a patient with an ATRT (patient 11). b Follow-up MRI scan at 6 months post-SRS with extensive edema. c The same MRI scan as in $\mathbf{b}$ after registering it with the original planning $\mathrm{CT}$ and displaying isodose curves. d-f Axial, coronal, and sagittal views of the 6-month follow-up MRI registered with the planning CT and displaying the 16 Gy line ( $80 \%$ isodose curve)
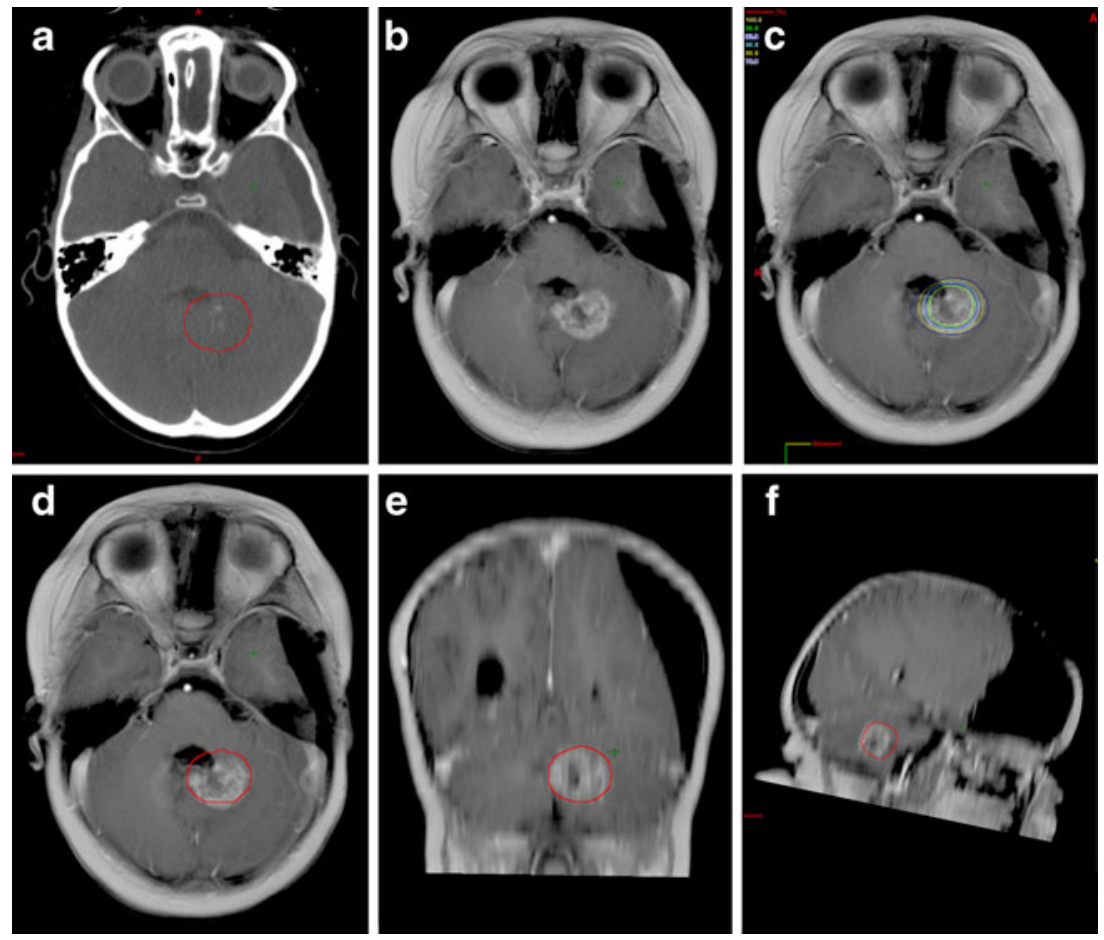

expected due to image registration and variable patient position during imaging. Regardless, it may be useful to provide tumor boards or neuroradiologists with a planning CT showing high-dose isodose curves in order to help evaluate for disease progression during MRI evaluation.

Previous research has demonstrated a similar pattern of lesion growth following SRS of adult intracranial malignancies. Ross et al. examined the imaging characteristics of 30 malignant gliomas and 35 intracranial metastases and found that $73 \%$ were larger a mean of 13 weeks following SRS and $22 \%$ of metastatic lesions were larger a mean of 10 weeks following SRS [25]. FDG-PET was also found to be unreliable in distinguishing radiation effect from tumor progression. Peterson et al. performed serial MRI examinations on 48 adult patients with 78 brain metastases and reported transient lesion growth in five metastases [24]. The literature describing imaging changes in pediatric patients is more sparse. Bakardjiev et al. analyzed 28 children who had been treated with SRS for low grade astrocytomas for MRI changes that could mimic disease progression and found that $43 \%$ of patients developed increased lesion size, increased signal enhancement, cysts or cavitations, and an increase in edema or mass effect on follow-up MRI [1]. They also reported that most patients with transient lesion enlargement could be identified by a lack of clinical symptoms. Thus, based on these studies, it appears that lesion enlargement following SRS is common, and primary intracranial tumors may have a higher rate of transient radiation edema than metastases. This may be attributed to the fact that metastases displace adjacent normal brain tissue, whereas primary intracranial tumors are largely infiltrative of brain parenchyma. Metastases may therefore leave minimal residual tissue damage, whereas the ablation of a primary tumor will likely leave a large cystic cavity that evolves over time as cells die. Since the brain is a devoid of lymphatics, it may take longer to clear cellular debris than extracranial sites, leading to the development of a prolonged inflammatory response.

There are several limitations to the current study. Our sample size is small and composed of a heterogeneous group of aggressive and benign primary pediatric brain tumors. As such, it is difficult to draw definitive conclusions for any one subgroup, as it is likely that each histological subtype responds differently to SRS. However, little data is available for MRI changes following pediatric SRS, and a broad overview of multiple tumor types may therefore provide an useful initial guideline for disease surveillance in these patients. A prospective evaluation with a larger well-defined cohort is warranted, particularly examining factors predictive of transient lesion enlargement.

In summary, we have followed the MRI changes of 21 pediatric brain tumors treated with SRS in an effort to characterize the evolution of imaging responses following therapy. The predominant pattern of change was a CR seen within 6 months of therapy. However, one third of lesions that showed signs of growth did not ultimately progress with one lesion developing a CR greater than 17 months following SRS. A lack of clinical symptoms and cystic change helped to distinguish transient radiation effect from disease progression. High isodose curves, particularly the 
16 Gy line, were found to encompass the extent of lesion edema, and may be useful to neuroradiologists or tumor boards when evaluating treatment response during serial MRI examinations.

Conflicts of interest notification Arno J. Mundt and Kevin T. Murphy have received honorariums from Varian Medical Systems for giving lectures. The Center for Advanced Radiotherapy Technologies receives research funding from Varian Medical Systems.

Open Access This article is distributed under the terms of the Creative Commons Attribution Noncommercial License which permits any noncommercial use, distribution, and reproduction in any medium, provided the original author(s) and source are credited.

\section{References}

1. Bakardjiev AI, Barnes PD, Goumnerova LC, Black PM, Scott RM, Pomeroy SL, Billett A, Loeffler JS, Tarbell NJ (1996) Magnetic resonance imaging changes after stereotactic radiation therapy for childhood low grade astrocytoma. Cancer 78:864-873

2. Baumann GS, Wara WM, Larson DA, Sneed PK, Gutin PH, Ciricillo SF, McDermott MW, Park E, Stalpers LJ, Verhey LJ, Smith V, Petti PL, Edwards MS (1996) Gamma knife radiosurgery in children. Pediatr Neurosurg 24:193-201

3. Belohlavek O, Simonova G, Kantorova I, Novotny J Jr, Liscak R (2003) Brain metastases after stereotactic radiosurgery using the Leksell gamma knife: can FDG PET help to differentiate radionecrosis from tumour progression? Eur J Nucl Med Mol Imaging 30:96-100

4. Bhat SR, Goodwin TL, Burwinkle TM, Lansdale MF, Dahl GV, Huhn SL, Gibbs IC, Donaldson SS, Rosenblum RK, Varni JW, Fisher PG (2005) Profile of daily life in children with brain tumors: an assessment of health-related quality of life. J Clin Oncol 23:5493-5500

5. CBTRUS (2007) Statistical Report: Primary Brain Tumors in the United States, 1998-2002. Central Brain Tumor Registry of the United States; wwwcbtrusorg

6. Dequesada IM, Quisling RG, Yachnis A, Friedman WA (2008) Can standard magnetic resonance imaging reliably distinguish recurrent tumor from radiation necrosis after radiosurgery for brain metastases? A radiographic-pathological study. Neurosurgery 63:898-903, discussion 904

7. Eder HG, Leber KA, Eustacchio S, Pendl G (2001) The role of gamma knife radiosurgery in children. Childs Nerv Syst 17:341346, discussion 347

8. Eisenhauer EA, Therasse P, Bogaerts J, Schwartz LH, Sargent D, Ford R, Dancey J, Arbuck S, Gwyther S, Mooney M, Rubinstein L, Shankar L, Dodd L, Kaplan R, Lacombe D, Verweij J (2009) New response evaluation criteria in solid tumours: revised RECIST guideline (version 1.1). Eur J Cancer 45:228-247

9. Flannery T, Kano H, Martin JJ, Niranjan A, Flickinger JC, Lunsford LD, Kondziolka D (2009) Boost radiosurgery as a strategy after failure of initial management of pediatric primitive neuroectodermal tumors. J Neurosurg Pediatr 3:205-210

10. Geenen MM, Cardous-Ubbink MC, Kremer LC, van den Bos C, van der Pal HJ, Heinen RC, Jaspers MW, Koning CC, Oldenburger F, Langeveld NE, Hart AA, Bakker PJ, Caron $\mathrm{HN}$, van Leeuwen FE (2007) Medical assessment of adverse health outcomes in long-term survivors of childhood cancer. JAMA 297:2705-2715

11. Giller CA, Berger BD, Pistenmaa DA, Sklar F, Weprin B, Shapiro K, Winick N, Mulne AF, Delp JL, Gilio JP, Gall KP, Dicke KA, Swift D, Sacco D, Harris-Henderson K, Bowers D (2005) Robotically guided radiosurgery for children. Pediatr Blood Cancer 45:304-310

12. Grabb PA, Lunsford LD, Albright AL, Kondziolka D, Flickinger JC (1996) Stereotactic radiosurgery for glial neoplasms of childhood. Neurosurgery 38:696-701, discussion 701-692

13. Gurney JG, Smith MA, Bunin GR (1999) CNS and Miscellaneous Intracranial and Intraspinal Neoplasms (Chapter in: Cancer Incidence and Survival among Children and Adolescents: United States SEER Program 1975-1995). National Cancer Institute, SEER Program, NIH Pub. No. 99-4649, Bethesda, MD

14. Harris OA, Adler JR (1996) Analysis of the proliferative potential of residual tumor after radiosurgery for intraparenchymal brain metastases. J Neurosurg 85:667-671

15. Kano H, Kondziolka D, Lobato-Polo J, Zorro O, Flickinger JC, Lunsford LD (2010) T1/T2 matching to differentiate tumor growth from radiation effects after stereotactic radiosurgery. Neurosurgery 66:486-491, discussion 491-482

16. Kano H, Niranjan A, Kondziolka D, Flickinger JC, Pollack IF, Jakacki RI, Lunsford LD (2009) Stereotactic radiosurgery for pilocytic astrocytomas part 2: outcomes in pediatric patients. J Neurooncol 95:219-229

17. Keshavarzi S, Meltzer H, Ben-Haim S, Newman CB, Lawson JD, Levy ML, Murphy K (2009) Initial clinical experience with frameless optically guided stereotactic radiosurgery/radiotherapy in pediatric patients. Childs Nerv Syst 25:837-844

18. Kimura T, Sako K, Tanaka K, Gotoh T, Yoshida H, Aburano T, Tanaka T, Arai H, Nakada T (2004) Evaluation of the response of metastatic brain tumors to stereotactic radiosurgery by proton magnetic resonance spectroscopy, 201TlCl single-photon emission computerized tomography, and gadolinium-enhanced magnetic resonance imaging. J Neurosurg 100:835-841

19. Kondziolka D, Lunsford LD, Flickinger JC (1990) Stereotactic radiosurgery in children and adolescents. Pediatr Neurosurg 16:219-221

20. Lawrence YR, Li XA, el Naqa I, Han CA, Marks LB, Merchant TE, Dicker AP (2010) Radiation dose-volume effects in the brain. Int J Radiat Oncol Biol Phys 76:S20-S27

21. Mansur DB, Rubin JB, Kidd EA, King AA, Hollander AS, Smyth MD, Limbrick DD, Park TS, Leonard JR (2010) Radiation Therapy for Pilocytic Astrocytomas of Childhood. Int J Radiat Oncol Biol Phys (in press)

22. Mueller S, Chang S (2009) Pediatric brain tumors: current treatment strategies and future therapeutic approaches. Neurotherapeutics 6:570-586

23. Oeffinger KC, Mertens AC, Sklar CA, Kawashima T, Hudson MM, Meadows AT, Friedman DL, Marina N, Hobbie W, KadanLottick NS, Schwartz CL, Leisenring W, Robison LL (2006) Chronic health conditions in adult survivors of childhood cancer. N Engl J Med 355:1572-1582

24. Peterson AM, Meltzer CC, Evanson EJ, Flickinger JC, Kondziolka D (1999) MR imaging response of brain metastases after gamma knife stereotactic radiosurgery. Radiology 211:807-814

25. Ross DA, Sandler HM, Balter JM, Hayman JA, Archer PG, Auer DL (2002) Imaging changes after stereotactic radiosurgery of primary and secondary malignant brain tumors. J Neurooncol 56:175-181

26. Schwartz RB, Holman BL, Polak JF, Garada BM, Schwartz MS, Folkerth R, Carvalho PA, Loeffler JS, Shrieve DC, Black PM, Alexander E 3rd (1998) Dual-isotope single-photon emission computerized tomography scanning in patients with glioblastoma multiforme: association with patient survival and histopathological characteristics of tumor after high-dose radiotherapy. J Neurosurg 89:60-68 
27. Somaza SC, Kondziolka D, Lunsford LD, Flickinger JC, Bissonette DJ, Albright AL (1996) Early outcomes after stereotactic radiosurgery for growing pilocytic astrocytomas in children. Pediatr Neurosurg 25:109-115

28. Terakawa Y, Tsuyuguchi N, Iwai Y, Yamanaka K, Higashiyama S, Takami T, Ohata K (2008) Diagnostic accuracy of 11Cmethionine PET for differentiation of recurrent brain tumors from radiation necrosis after radiotherapy. J Nucl Med 49:694-699
29. Tsuyuguchi N, Sunada I, Iwai Y, Yamanaka K, Tanaka K, Takami T, Otsuka Y, Sakamoto S, Ohata K, Goto T, Hara M (2003) Methionine positron emission tomography of recurrent metastatic brain tumor and radiation necrosis after stereotactic radiosurgery: is a differential diagnosis possible? J Neurosurg 98:1056-1064

30. Turner CD, Rey-Casserly C, Liptak CC, Chordas C (2009) Late effects of therapy for pediatric brain tumor survivors. J Child Neurol 24:1455-1463 